\title{
Challenges in the Management of Syphilis
}

\author{
Sankaranantham $\mathbf{M}^{*}$ \\ Sree Mookambika Institute of Medical Sciences. India
}

*Corresponding author: Sankaranantham M, Professor of Dermatology, Venereology and Leprosy, Institute of Medical Sciences, Kulasekharam, Kanyakumari district, India.

Submission: 望 July 13, 2018; Published: 制 August 17, 2018

\section{Introduction}

Even after 70 years of antibiotic therapy and with advanced diagnostic procedures the management and follow up of syphilis poses an immense problem.

\section{Challenges}

Syphilis can be treated to the point of presumptive cure as there is no test for cure [1]. As per various recommendations, still Penicillin is the drug of choice to treat Syphilis [2,3]. Other treatments are considered as inferior, because of poor penetration into placental and blood brain barrier. When Penicillin cannot be used (Hypersensitivity or non-availability), alternate ideal drugs are not available to prevent congenital syphilis and neuro-syphilis. Desensitization procedures are cumbersome and not able to be followed at many centers. In one of my studies [4], out of 180 cases of syphilitic serology positive individuals during the period of January 2010 to December 2017, 16 were found to be biological false positive. 164 (91.1\%) were found to have real syphilis (not associated with HIV) as per Trponemal tests. 4 were also were having Diabetes Mallitus. 10 patients were in early syphilis (Two were having Primary syphilis, seven were with secondary manifestations and one was in early latent stage) and another 5 were having late manifestations ( Three were having Coronary ostial stenosis diagnosed by angiogram, one case of aneurysm of aorta, one case of optic syphilis) and 149 were in late latent stage of syphilis without any manifestations. Most of the cases referred from either obstetricians, surgeons through preoperative screening or an accidental finding in routine checkup. After anti-syphilitic treatment, 56 were lost to follow up and two dropped out before treatment. Among the 106 who were followed up, 22 (all 10 early syphilitics and 12 late latent syphilitics) had attained either a considerable fall in titer or a reversal to nonreactive status for Syphilis whereas another 84 (79.2\%) are still on my follow up for one year and in some cases up to 5 years with persistent serology either in same titer or a raise in titer. The response to treatment and sero-reversion in cases of early syphilis is prompt, when compared to late or late latent syphilis. Among these 84 patients, 17 were further treated either with Injection Procaine Penicillin daily for 21 days or with InjBenzy Penicillin G 20 lakhs units IV twice daily or with Doxycyclins $100 \mathrm{mg}$ twice daily for 30 days in case of late syphilis and in one case with Injection Ceftrixone 1 gram daily IM for 3 weeks without any benefit. Resistance to various antibiotics in the management of syphilis was reported already [5,6]. Recently high doses of Amoxycillin 3grams a day per oral along with $750 \mathrm{mg}$ of Probenicid 14 days in case of early syphilis and 4 weeks in case of late syphilis without many side effects tried with good success [7]. Fortunately in my series no individual with this persistent serological test report had not gone for late manifested syphilis even though some have previous manifestations and some had coincidental cardiovascular problems like triple vessel diseases, valvular lesions etc. which were not anyway related to syphilis. Whether Treponemes are becoming resistant to Penicillin or the host response was poor? Recent guidelines of WHO or Center for Disease Control, fail to consider special attention to Cardiovascular Syphilis for its management in their guidelines. Therapeutic Paradox is another problem when we treat Cardiovascular, Neuro and Optic Syphilis (apart from Jarish Herxheimer reactions) [8]. Recent years once again incidence of early Syphilis had been in an ascending trend throughout the world. $30 \%$ of either missed or inadequately treated cases of old infection are appearing sporadically with late manifestations have to be considered and have to be guided properly with regards to treatment.

Diagnosis of syphilis is also posing difficulties. In congenital syphilis, passive transmission of syphilitic mother's antibodies has to be ruled out with FTA ABS IgM which is not available in all countries. Procaine penicillin was not available in many parts world. Dark field examination for the presence of Treponemes in very early primary ulcer was not possible as the technicians and specialists are not familiar with treponemes poses difficulty in the diagnosis of sero-negative chancre. Nowadays nonspecific treponemal tests were not performed routinely for screening for syphilis. In its place a Treponemal card test is used unless or otherwise the Rapid Plasma regain test is asked for. Even though it is easy to perform, rapid simple and less costly, false positive and negative results are more common and this card test has no prognostic value. So once again we have to go for regain test (Reverse algorithm). Lastly, in the presence of HIV infection, syphilis poses a lot of problems in the diagnosis, management and for the follow up. 
The questions posed in front of us are

1. Whether we can take that syphilis had been cured completely or not in presence of the persistence of serology test positive in spite of the recommended doses?

2. How to convince the patient that he/she had been cured when the serology test reactive in same dilutions?

3. How to convince other specialty doctors that this patient had been cured and the individual warrants no further treatment when the test reports not support our statement?

The only answer is to go for a large scale multi-centric study in this regard.

\section{Reference}

1. Stokes JH, Beerman H (2010) Ingraham NR modern syphilology. ( $3^{\text {rd }}$ edn), Saunders WB, Philadelphia, Pennsylvania, USA, p. 1.
2. (2016) WHO guidelines for the treatment of Treponema pallidum (syphilis). Geneva, Switzerland.

3. CDC Guidelines for 2015 Sexually transmitted diseases treatment guidelines.

4. Sankaranantham M (2018) Persistence syphilitic serology in late syphilis even after the recommended treatment. Rep Sys Sex Dis Int J 2(3): 33-34

5. Stamm LV (2010) Global challenge of antibiotic resistant Treponema pallidum. Anitmicrob Agents Chemother 54(2): 583-589.

6. Stamm LV, Stapleton JT, Brasford PJ Jr (1988) In vitro assay to demonstrate high-level erythromycin resistance in a clinical isolate of Treponema Pallidum. Anitmicrob Agents Chemother 32(2): 164-169.

7. Tanizaki R, Nishijima T, Aoki T, Teruya K, Kikuchi Y, et al. (2015) Oral amoxicillin plus probenecid is highly effective for syphilis in patients with HIV infection. Clinical Infectious Diseases 61(2): 177-183.

8. Catterall RD (1978) A short text book of Venereology. ( $\left.2^{\text {nd }} e d n\right)$.

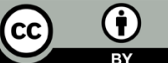

Creative Commons Attribution 4.0 International License

For possible submissions Click Here

\section{Submit Article}

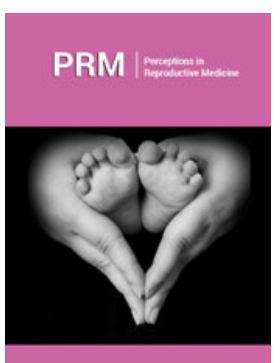

\section{Perceptions in Reproductive Medicine}

\section{Benefits of Publishing with us}

- High-level peer review and editorial services

- Freely accessible online immediately upon publication

- Authors retain the copyright to their work

- Licensing it under a Creative Commons license

- Visibility through different online platforms 